\title{
The status of academic integrity amongst nursing students at a nursing education institution in the Western Cape
}

\author{
Authors: \\ Cecilia J. Theart ${ }^{1}$ \\ Ilze Smit ${ }^{1}$ \\ Affilliations: \\ ${ }^{1}$ Faculty of Health Sciences, \\ Stellenbosch University, \\ South Africa \\ Correspondence to: \\ Cecilia Theart \\ Email: \\ cjtheart@pgwc.gov.za \\ Postal address: \\ PO Box 562, Bellville 7535, \\ South Africa \\ Dates: \\ Received: 28 July 2011 \\ Accepted: 12 Dec. 2011 \\ Published: 20 June 2012 \\ How to cite this article: \\ Theart, C.J. \& Smit, I., 2012, \\ 'The status of academic \\ integrity amongst nursing \\ students at a nursing \\ education institution in the \\ Western Cape', Curationis \\ 35(1), Art. \#27, 8 pages. \\ http://dx.doi.org/10.4102/ \\ curationis.v35i1.27
}

(C) 2012. The Authors. Licensee: AOSIS OpenJournals. This work is licensed under the Creative Commons Attribution License.
Honesty is regarded as a basic ethical value in all educational programmes, and academic integrity is of undisputed importance in educational environments. The literature reviewed revealed that academic dishonesty is wide-ranging and also encountered in the nursing education environment. This phenomenon is of concern to the nursing fraternity because of the proven positive correlation between unethical academic practices and future unethical professional behaviour. Limited research data regarding academic dishonesty at nursing education institutions in South Africa and this correlation motivated the present study. The purpose was to examine the status of academic integrity amongst nursing students at a nursing education institution in the Western Cape. Formulated objectives guided investigation of several variables which impact upon academic integrity, for example the incidence of and student perceptions around academic dishonesty.

A quantitative, descriptive survey design was used, with a self-reported questionnaire (based on literature review and study objectives) designed to obtain information about academic dishonesty. Provision was also made for qualitative input from the respondents by including three open-ended questions.

It was found that academic dishonesty was a reality at the nursing education institution where this study was done. Cheating associated with plagiarism and assignments was identified as the main problem area. An unacceptably high level of dishonesty in completion of practical records was also an area of concern. The main recommendations are development and implementation of a code of honour and implementation of comprehensive academic integrity policies at the nursing education institution, with practical measures aimed at combating cheating in tests and examinations.

\section{Introduction and background}

Academic integrity is described as the prevalence of honesty in all academic matters (Turner \& Beemsterboer 2003:1122). Violation of academic integrity - in other words, academic dishonesty - commonly manifests as cheating in examinations and/or committing plagiarism and forgery, resulting in the student not acquiring the expected knowledge (Turner \& Beemsterboer 2003:1122). Therefore, in order to explore the status of academic integrity, the extent of academic dishonesty needed to be established.

Academic integrity is an undisputed ethical imperative in the educational environment. However, it is well-established in the literature that, generally, academic dishonesty is a growing problem at academic institutions all over the world (Burns et al. 1998:596; Lim \& See 2001:272; McCabe 2009:614; McCabe, Butterfield \& Treviño 2006:299; Olasehinde-Williams, Abdullah \& Owolabi 2003:77; Whitley 1998:238).

According to Searle (2000:95), nursing is deemed a highly ethical profession and relies on the moral integrity of individual practitioners to provide safe nursing care. Some researchers expected that academic dishonesty would be less common amongst nursing students (Fontana 2009:181; Hilbert 1987:43; McCabe 2009:616), and this was initially confirmed by Hilbert (1985:232), who found that incidents of academic dishonesty occurred less frequently amongst nursing students compared to the general student body. However, later studies established that academic dishonesty was also a common occurrence amongst nursing students (Bailey 2001:127; Brown 2002:7; McCabe 2009:616). The importance of these findings for nursing lies in the potential for unethical classroom behaviour to be transmitted to clinical practice, causing a threat to the safety and well-being of patients (Bailey 2001:128). Researchers identified existence of a positive correlation between unethical academic practices and future professional unethical behaviour (Nonis \& Swift 2001:76). 
Trust plays a vital role in the relationship between nurse and health care consumer, since it implies that the nurse's competency, professional morality and integrity are above suspicion, and she is expected to act ethically at all times (Searle 2000:97,227). Nursing students become professional nurse practitioners bound to ethical codes of practice, and health care consumers must be able to trust them to practice their profession with integrity at all times (Kenny 2007:14). Therefore, academic dishonesty in nursing education with consequent questioning of the nurse's honesty and professional integrity - causes great concern in the nursing profession (Kenny 2007:17).

\section{Problem statement}

Guided by the literature study, a perception was formed that, academic dishonesty is a wide-ranging practice globally that is also prevalent in the nursing education environment (McCabe 2009:617). This perception was strengthened by the researcher's personal experience of academic dishonesty amongst nursing students. In South Africa to date no studies have explored academic dishonesty amongst nursing students. However, on the basis of international studies and the researcher's personal experience, a justifiable inference was made that the practice of academic dishonesty could prevail at nursing education institutions in South Africa. This conjecture, together with the previously mentioned correlation between academic dishonesty and unethical professional conduct, motivated the researcher (C.J.T., a nurse educator) to investigate the prevalence of academic dishonesty amongst nursing students. It was hoped that the study would result in greater insight into the problem, and that it would suggest contextually relevant interventions to address academic dishonesty, thus enhancing academic integrity.

\section{Purpose and objectives of the study}

The purpose of this study was to explore academic integrity amongst nursing students at a nursing education institution in the Western Cape.

The overall research question directing the objectives of the study was: What is the status of academic integrity amongst nursing students at a nursing education institution in the Western Cape?

The objectives of the study were to:

- determine the incidence of academic dishonesty amongst nursing students;

- investigate the individual and contextual factors that have an influence on academic dishonesty amongst nursing students;

- determine students' knowledge of institutional policies regarding academic dishonesty;

- determine students' understanding of plagiarism and referencing;

- determine students' attitudes towards cheating; and

- explore students' recommendations regarding prevention of cheating.

\section{Significance of the study}

This study meets the need for contextually relevant research into the academic integrity of nursing students in South Africa. Existence of academic dishonesty amongst nursing students was demonstrated. As such, the study increases awareness around the problem and highlights the need for nursing education institutions to accept the challenge of establishing a learning environment where academic integrity is highly valued and zealously protected. This must be done so that, ultimately, ethical nursing practitioners are developed for the future. The study also suggests contextually relevant interventions to address academic dishonesty, thus enhancing academic integrity.

\section{Definition of key concepts}

Academic integrity: Honesty by pre-registration student nurses in all activities related to the academic programme.

Academic dishonesty: The terms 'academic dishonesty', 'cheating' and 'plagiarism' are often used interchangeably in the literature. Lambert, Hogan and Barton (2003:2) define academic dishonesty as 'any fraudulent actions or attempts by a student to use unauthorised or unacceptable means in any academic work'. Logue (2004:40) defines plagiarism as 'the intentional or unintentional use of another's work or ideas, published or unpublished, without clearly acknowledging the source of that work or idea'. Schmidt (2006:1) classifies plagiarism as a form of cheating. Based on the above definitions, the term 'academic dishonesty' included all forms of cheating behaviour as well as plagiarism.

Pre-registration student: Students registered in a four-year course leading to registration as a nurse (general, psychiatric and community) and a midwife, under Regulation 425 of 22 February 1985 in terms of Section 45 (1) of the Nursing Act, 1978 (Act 50 of 1978) (South African Government, 1978).

\section{Research method and design Design}

A quantitative, descriptive survey design was used to explore the extent of academic dishonesty amongst nursing students. Qualitative input aimed at supplementing the primary quantitative data was obtained from respondents. Since the primary purpose was to collect information, no specific theory was used or tested.

\section{Materials}

The study population included all pre-registration nursing students in the second-, third- and fourth-year groups at a specific nursing education institution in the Western Cape. A large sample of 550 students was obtained, using a nonrandom convenience sampling technique to draw a sample of $80 \%$ from each of the above-mentioned student groups. The rationale for utilising a non-random sampling technique was to protect the anonymity of the respondents. The sensitive nature of the topic rendered anonymity very important in order to elicit honest answers. A large sample of $80 \%$ was 
employed to increase the representation of the sample. The first-year student group was not considered since they did not meet the inclusion criteria of having completed at least one theory examination, one theory assignment and one theory test at this educational institution.

\section{Data collection methods}

A questionnaire comprising 61 Likert-type questions was utilised to obtain self-reported information on academic dishonesty. It was designed in a way that allowed specific analysis of different forms of academic dishonesty, for example cheating behaviour and plagiarism. Some questions were included to determine potential individual influential factors such as age, gender, home language and year of training. Other questions aimed at eliciting contextual information regarding academic dishonesty, addressing, for example, incidents of cheating, the prevalence of observed academic dishonesty, the perceived seriousness of cheating, the influence of peer behaviour, willingness to report academic dishonesty, motivation for cheating, perceived deterrent effect of penalties, and knowledge of institutional policies regarding academic dishonesty. Three open-ended questions were included in the questionnaire to generate more in-depth qualitative data (Babbie 2007:246). These questions investigated the respondents' understanding of the term 'plagiarism', their feelings regarding cheating, and their recommendations to prevent academic cheating amongst students.

The most important motivation for using a questionnaire was the sense of security created by the anonymity accompanying it which, according to Brink (2006:147), is vital for eliciting honest answers from respondents.

In an effort to secure an adequate response rate and to maintain consistency, data collection took place during scheduled classes. The first $80 \%$ of the various year groups of students who entered the classroom received questionnaires. The researcher explained the purpose of the research and the research procedure. The respondents were informed that their participation was voluntary, and they were assured that their anonymity would be protected. All the respondents' questions were addressed and the researcher requested respect for the privacy of respondents in completing their questionnaires. Time was granted to complete the questionnaires, which were then posted into a sealed box.

\section{Data analysis}

Descriptive statistics and appropriate inferential statistical tests, for example analysis of variance (ANOVA), were used in analysing the data. The data were displayed in the form of histograms and/or frequency tables.

The raw data generated by the open-ended questions in the questionnaires were intended to supplement the quantitative data, and were not regarded as true qualitative research. However, they were managed and categorised using the basic principles of Tesch's approach to qualitative data analysis (Poggenpoel 1998:343). The researcher compiled a list of topics, abbreviated as codes, and these codes were written next to appropriate portions of the text. Finally, several categories of responses were identified and the frequency of these was recorded.

\section{Context of the study}

The study was conducted amongst pre-registration nursing students at a nursing education institution in the Western Cape.

\section{Ethical considerations}

Ethical approval was obtained before data collection commenced. Consent was also obtained from the head of the institution where the research was conducted. Respondents were protected by ensuring their privacy, anonymity, confidentiality, and by acquiring informed consent from them (Mouton 2001:243).

Explaining to them that participation was voluntary and completion of the questionnaire was optional protected the respondents' right to privacy. The protection and safekeeping of the acquired information were also explained to the respondents. Anonymity and confidentiality were ensured through anonymous completion of questionnaires, and all the questionnaires were collected by posting them into a sealed box (Mouton 2001:234). The respondents' confidentiality was further protected by non-disclosure of the name of the educational institution where the study was done. Only the researcher, statistician and research supervisor had access to the collected data.

Informed consent was ensured by explaining the aim of the study, the procedure for data collection, and information on how the results would be disseminated to the respondents. Informed consent was assumed upon completion of the questionnaire (Mouton 2001:244).

\section{Validity and reliability}

In order to ensure reliability, the items included in the questionnaire were based on analysis of research studies on academic dishonesty done by McCabe and Treviño (1997:380), Lim and See (2001:264) and Newstead, FranklinStokes and Armstead (1996:232). The questions were tested in a pilot study to make sure that the respondents understood them. Consistency during data collection was enhanced by involving only the researcher in the collection of data and utilising scheduled class time to ensure that methods and procedures of data collection were the same for all respondents (Basavanthappa 2007:364).

In order to ensure content and face validity, the questionnaire was based on a literature review as well as on the objectives formulated for the study. A statistician, the supervisor, as 
well as other experts in research methodology and nursing education, analysed the questionnaire. A pilot study targeting 28 students yielded a return rate of 39\% (11 respondents). This fairly low response rate prompted the researcher to increase the sample for the main study to $80 \%$. In addition, some minor changes were made to the questionnaire.

\section{Discussion of results Demographic information}

The respondents comprised $84 \%$ females and $16 \%$ males. First languages of the respondents were Xhosa (51\%), Afrikaans (37\%), English (9\%) and other (3\%). Most (45\%) were in their second year, 22\% in their third year and 33\% in the fourth year of training. The mean age of the respondents was 25 years, with most ( $46 \%$ ) in the age group $21-25$ years and only one respondent in the 46 year -50 year age group.

\section{Incidence of academic dishonesty}

The majority of respondents (88\%) indicated that they had committed one of the surveyed cheating activities at least once; only $12 \%$ reported that they had never been involved in any form of cheating. These findings were congruent with those of past studies carried out with students in courses other than nursing. For example, Lim and See (2001:267) reported that almost all of the students had committed one form of cheating at least once. Lambert et al. (2003:12) found an overall involvement in cheating behaviour of $83 \%$. However, the involvement in cheating practices by pre-registration nursing students in the current study is considerably higher when compared to previous research amongst exclusively nursing students. McCabe (2009:617) found that $58 \%$ of undergraduate nursing students were engaged in at least one of the surveyed cheating behaviours, whereas Brown (2002:7) reported that only $8-13 \%$ of nursing students admitted to being involved in cheating behaviour.

Table 1 illustrates the forms of cheating behaviour exhibited and witnessed by the respondents, from most to least frequently occurring. It is noteworthy that cheating behaviours tantamount to plagiarism $(60 \%$ and $57 \%)$ and dishonesty related to assignments (45\%) were the two most common forms of cheating committed by students in this study. These findings are generally consistent with previous research; most researchers also identified paraphrasing of material without acknowledging the source as one of the most common cheating behaviours (Hilbert 1985:231; Lim \& See 2001:268; McCabe 2009:617; Newstead et al. 1996:231). Dishonest behaviour related to assignments also features high on the frequency rate in previous studies (Hilbert 1985:231; Lim \& See 2001:268; McCabe 2009:617; Newstead et al. 1996:232). Researchers have acknowledged that the high incidence of plagiarism might be due to the fact that students possibly do not understand plagiarism (Paterson, Taylor \& Usick 2003:157), or do not understand the seriousness of it (Park, 2003:483). Previous research has also indicated that students often regard plagiarism and cheating in assignments as less serious acts of academic dishonesty (McCabe 2009:620).

The least common cheating behaviour (3\%) reported by respondents was using unauthorised crib notes in a test or examination. This was also the least witnessed (15\%) cheating behaviour (Table 2). However, a comparison of the respondents' awareness of cheating by other students (30\%) (Table 2) with their self-reported personal engagement in cheating $(6 \%)$ in tests and examinations indicated that it is possible that personal dishonesty was under-reported. The same trend was found amongst respondents who indicated awareness of other students bringing unauthorised crib notes into a test or examination (16\%) (Table 2), compared to only $4 \%$ who admitted to engaging in this behaviour themselves. Similarly, more respondents were aware of other students using unauthorised crib notes $(15 \%)$ than the $3 \%$ of respondents who admitted that they had been involved in this behaviour (Table 2). Brown (2002:7) also found that a large number of students reported that they had seen other students cheat, whilst a much smaller number admitted to cheating themselves.

TABLE 1: Incidence of cheating behaviours.

\begin{tabular}{|c|c|c|}
\hline Items & $f$ & $\%$ \\
\hline $\begin{array}{l}\text { Copying ideas from any sources without acknowledging } \\
\text { the original author }\end{array}$ & 237 & 60 \\
\hline $\begin{array}{l}\text { Copying word for word from any original sources and } \\
\text { not using quotation marks }\end{array}$ & 224 & 57 \\
\hline $\begin{array}{l}\text { Working together with other students on a homework } \\
\text { assignment that was supposed to be done individually }\end{array}$ & 159 & 45 \\
\hline $\begin{array}{l}\text { Dishonesty in any way with completing one's practical } \\
\text { workbook }\end{array}$ & 134 & 34 \\
\hline $\begin{array}{l}\text { Using material from another student's paper without } \\
\text { acknowledging the original author }\end{array}$ & 103 & 27 \\
\hline Writing an assignment for someone else & 74 & 20 \\
\hline $\begin{array}{l}\text { Allowing another student to copy from one's work } \\
\text { during a test or examination }\end{array}$ & 53 & 14 \\
\hline $\begin{array}{l}\text { Giving another student answers in a test or } \\
\text { examination with the help of signals }\end{array}$ & 57 & 14 \\
\hline $\begin{array}{l}\text { Submitting a paper written by someone else as } \\
\text { one's own }\end{array}$ & 23 & 8 \\
\hline $\begin{array}{l}\text { Lying about medical or other circumstances to defer a } \\
\text { test or examination in order to have more time to study } \\
\text { for it }\end{array}$ & 29 & 7 \\
\hline Copying from another student during a test or examination & 18 & 6 \\
\hline Submitting another student's work as one's own & 10 & 4 \\
\hline $\begin{array}{l}\text { Bringing unauthorised crib notes into a test or examination } \\
\text { venue }\end{array}$ & 9 & 4 \\
\hline Using unauthorised crib notes during a test or examination & 12 & 3 \\
\hline
\end{tabular}

$f$, frequency.

TABLE 2: Awareness of cheating behaviours by others.

\begin{tabular}{lcc}
\hline Items & $f$ & $\mathbf{\%}$ \\
\hline $\begin{array}{l}\text { Awareness of another student being dishonest when } \\
\text { completing the practical workbook }\end{array}$ & 223 & 56 \\
$\begin{array}{l}\text { Awareness of another student allowing someone else } \\
\text { to copy their assignment }\end{array}$ & 155 & 30 \\
$\begin{array}{l}\text { Awareness of another student copying from someone } \\
\text { else during a test or an examination }\end{array}$ & 120 & 30 \\
$\begin{array}{l}\text { Awareness of another student helping someone } \\
\text { else to cheat in a test }\end{array}$ & 67 & 17 \\
$\begin{array}{l}\text { Awareness of another student bringing unauthorised } \\
\text { crib notes into a test or examination venue }\end{array}$ & 63 & 16 \\
$\begin{array}{l}\text { Awareness of another student using unauthorised crib } \\
\text { notes during a test or examination }\end{array}$ & 62 & 15 \\
\hline
\end{tabular}

$f$, frequency. 
A large number of respondents (34\%) reported dishonesty in completion of their practical workbooks, and $56 \%$ of the respondents reported that they had witnessed other students being dishonest when completing them. This finding has implications for their competency as future independent nursing practitioners. A possible explanation for the dishonesty in recording the practical sessions could be that pre-registration nursing students fail to see the importance of the practical component of their nursing studies. This suggestion is supported by the following response of a student to an open-ended question regarding their feelings about students getting away with cheating: 'For the practical book I don't feel bad because some things they expect us to do are impossible, e.g. third-year (practical) book we all have cheated.'

\section{Factors influencing academic integrity}

\section{Individual factors}

The relationships between academic dishonesty and gender, home language, current level of training and age were explored. The results pertaining to gender indicated that males were significantly more likely to cheat than females. An appropriate ANOVA revealed a probability value of $p=0.02$ (smaller than the significance level of 0.05).

This finding is supported by previous studies that also found that males cheated more than females (Burns et al. 1998:596; McCabe \& Trevino 1997:388; Newstead et al. 1996:233; Nonis \& Swift 2001:72; Lim \& See 2001:270; Olasehinde-Williams et al. 2003:76; Whitley 1998:242). On the other hand, several studies found no significant difference between the cheating behaviour of males and females (Blankenship \& Whitley 2000:6; Hilbert 1987:42; McCabe 2009:618). Only one study was identified where it was found that females cheated more than males (Hilbert 1985:231). It seems from the divergent results of previous studies that the significance of gender as a predictor of cheating behaviour is still contentious.

No significant relationship was found between academic dishonesty and home language, current year of study, or age. Although the non-significant finding relating to age is supported by two previous studies conducted exclusively amongst nursing students (Daniel, Adams \& Smith 1994:286; Hilbert 1987:43), most previous studies suggest that younger first- and second-year students display more cheating behaviour than mature students (McCabe \& Trevino 1997:388; Newstead et al. 1996:233; Nonis \& Swift 2001:72; Whitley 1998:239).

\section{Contextual factors}

Academic success: Pressure to succeed academically (84\% of respondents) was indicated as a major factor influencing the decision to engage in cheating behaviour (see Table 3). This corresponds with previous research where pressure to achieve high marks was also identified as one of the most important reasons for cheating (Hilbert 1987:42; Newstead et al. 1996:233; Whitley 1998:243).
Consistent with the findings of Harding et al. (2004:315), Newstead et al. (1996:233); and Tanner (2004:291), the current research also identified the limited time available to study (74\% of respondents) as a major influence in students' cheating behaviour.

Status amongst peers: Most respondents (71\%) indicated that the fear of losing status amongst peers would cause them to engage in cheating behaviour. This finding is similar to previous research on the influence of peer behaviour on academic dishonesty (McCabe et al. 2006:300; McCabe \& Trevino 1997:391).

An interesting finding in the current study was that peer pressure made respondents more willing to assist friends with their assignments illegally (49\%) than to allow them to copy their assignments (19\%), or let friends copy their answers in tests or examinations (15\%). This may be related to the notion that students regard certain forms of academic dishonesty as more serious than others.

Impact of 'successful' cheating: Most (71\%) were of the opinion that the realisation that students got away with cheating would cause other students to engage in cheating behaviour. However, $85 \%$ indicated that if other students got away with cheating, it would not cause them to cheat. Although Jordan (2001:244) found a strong positive relation between cheating and witnessing other students cheat, it was difficult to relate this finding to the current study because of the above-mentioned contradictory views of the respondents. In summary, it can be concluded that all of the contextual factors portrayed in Table 3 played a major role in the cheating behaviour of the nursing students.

\section{Knowledge of institutional policies regarding academic dishonesty}

Most respondents indicated that they were aware of the institutional policies regarding referencing of sources $(71 \%)$, student conduct in assessment venues (92\%), and the penalties for academic dishonesty (71\%). They were generally better acquainted with the policies guiding conduct in assessment venues than those related to referencing of sources or penalties for academic dishonesty. Jordan (2001:243) found that students who had more knowledge of institutional policy cheated less, and vice versa. Therefore the above findings might explain why transgressions related to plagiarism were found to be more common than those related to examinations and tests.

TABLE 3: Opinion of respondents regarding contextual influences on cheating behaviours.

\begin{tabular}{ll}
\hline Reasons students engage in cheating behaviour & $\mathbf{\%}$ \\
\hline The pressure to succeed academically & 84 \\
The large amount of study material they have to master & 83 \\
The difficult learning material they have to study & 75 \\
The limited time they have to study & 74 \\
Other students getting away with it & 71 \\
Fear of losing status amongst peers & 71 \\
Their negative attitude towards assignments and tests & 69 \\
Having to pay back their bursary when they fail. & 64 \\
\hline
\end{tabular}




\section{Students' understanding of plagiarism and referencing}

Most of the respondents indicated that they knew what plagiarism was (83\%), and they displayed fairly good understanding in their explanations of the term 'plagiarism'. Replies to the questions related to referencing displayed a greater uncertainty from the respondents, with $72 \%$ indicating that they knew how to reference ideas from other authors, and $64 \%$ indicating that they knew how to reference direct quotations.

The responses to these questions revealed that students are not ignorant about the meaning of plagiarism or referencing. However, the researcher's experience at the setting where this study was conducted is that most students did not reference their sources at all, or did so very poorly. The reason for this may be tolerance on the part of faculty combined with laziness, and in some cases a lack of knowledge on the part of the student, rather than intentional cheating.

\section{Students' attitudes towards cheating}

The fact that most of the respondents felt that there is no justification for cheating suggests a general attitude of intolerance towards cheating. This finding corresponds with previous research on justifications for academic dishonesty (Jordan 2001:242). However, the finding that $25 \%$ of respondents felt that cheating might be justified in certain circumstances is significant in the light of other research findings. Lambert et al. (2003:14) found that there is a significant relationship between justification and the level of cheating. Whitley (1998:245) also found that students with so-called 'neutralising attitudes' (beliefs that cheating can be rationalised and justified) were more likely to cheat than students who felt that there is no justification for cheating.

Respondents were also asked to explain in their own words how they felt about the fact that some students got away with cheating. Some responses portrayed insight by indicating that cheating behaviour could extend into future practice and cause future practitioners to have inadequate knowledge. However, the majority of the respondents showed poor insight, with responses indicating that cheating does not matter, or that cheating was unfair towards other hardworking students. The following are some examples of the less insightful comments in response to the open-ended question (quoted verbatim):

'I could honestly say it's their luck. I don't find any reason to be emotional about it because in the end it's their choice.'

'It's unfair towards the students who are struggling hard to become something in life.'

These responses led the researcher to question the motivation behind the respondents' apparent attitude of intolerance towards cheating. Were they intolerant of cheating because of the 'unfairness' of cheating towards others, or were they intolerant because cheating is unethical behaviour?

It is worth mentioning that although the respondents were of the opinion that cheating is 'unfair' towards other students, they were not willing to report them. Most respondents indicated that they would not report another student to the lecturer if they witnessed them cheating in tests and examinations (66\%) or with their assignments (72\%). A possible explanation could be the influence of peer pressure. These findings are generally consistent with those from previous research on students' willingness to report their peers. Lim and See (2001:271) found that only $1.7 \%$ of respondents would report someone found cheating. McCabe et al. (2006:301) also reported that the vast majority of respondents were unwilling to report cheating amongst their peers.

A high percentage of respondents $(92 \%)$ indicated that they would feel guilty if they had cheated. This finding is significant in view of the high cheating rate and the apparent indifference towards academic dishonesty reflected in the above discussion.

It can be concluded that there is ambivalence in the respondents' attitudes toward cheating. On the one hand, most of the respondents indicated that there was no justification for cheating, suggesting intolerance of cheating. On the other hand, an indifference towards cheating is evident from their responses regarding students getting away with cheating, as well as their unwillingness to report cheating by other students that they witnessed. Once again, this may be more indicative of misplaced loyalty than indifference.

\section{Prevention of cheating}

In the light of the high cheating rate reported by the respondents, some interesting findings were that $83 \%$ of respondents indicated that students were afraid of being caught cheating; $75 \%$ believed that cheaters would get caught; and $73 \%$ were of the opinion that students are severely penalised when caught cheating. It seems that despite their fear of being caught and their belief that they would be severely penalised, students still persist with cheating behaviour.

Most of the respondents (79\%) were of the opinion that severe penalties would prevent students from cheating, and in the open-ended questions they also suggested strict application of punitive measures to prevent cheating. Other researchers also identified fear of being caught and imposition of severe penalties as major deterring factors with regard to engagement in cheating behaviour (Burns et al. 1998:595; Harding et al. 2004:315; McCabe, Trevino \& Butterfield 2001:222). Respondents also called for other preventative measures, such as searching students for unauthorised crib notes, maintenance of large spaces between desks, and strict invigilation during tests and examinations. Researchers in previous studies identified similar interventions to prevent cheating during tests and examinations (Brown 2002:7; Hilbert 1987:43).

A large number of respondents were in agreement that monitoring of peer behaviour $(66 \%)$ and introduction of a code of honour (65\%) would prevent students from cheating. 
This is strongly supported by previous research, which indicated that the prevalence of cheating behaviours was significantly reduced by proper implementation of codes of honour as well as monitoring by peers (Hall \& Kuh 1998:10; McCabe \& Trevino 1997:393; McCabe et al. 2001:224; Turner et al. 2003:1127).

Eight respondents were of the opinion that nothing should be done to prevent cheating. Although a very small minority, this is an alarming finding in the light of the high premium that is placed on honesty and integrity in the nursing profession. Previous research strongly supported the promotion of academic integrity amongst students by lecturers setting and applying ethical standards and modelling ethical behaviour in the classroom. This would help with the process of character building and moral fortification of the nursing student (Gaberson 1997:17; Lewenson, Truglio-Londrigan \& Singleton 2005:91; Nonis \& Swift 2001:75).

Some of the other strategies that respondents identified in responses to the open-ended question as ways to minimise cheating and plagiarism were:

- reduction of the workload of students;

- more time for students to study for tests and examinations;

- teaching proper referencing techniques to students;

- offering extra classes; and

- lecturers ensuring that students understand the work.

In summary, students generally recommended disciplinary, punitive and strict control measures during tests and examinations as major deterring strategies for cheating. The majority were also in agreement that institution of academic integrity policies and a code of honour would play an important role in curbing academic dishonesty.

\section{Limitations of the study}

A limitation of the study was the vulnerability to socially desirable response bias because of the sensitive nature of the topic. This may have resulted in under-reporting of cheating during tests and examinations. The researcher attempted to avoid this problem by guaranteeing complete anonymity and emphasising the importance of honest answers to the questions.

A limitation arising from the use of a self-reported questionnaire was that some respondents provided incomplete demographical data, did not complete all the closed-ended questions, and did not answer the open-ended questions.

\section{Recommendations}

The main recommendations that emerged from the findings of this study are as follows:

- Faculty together with students should develop and implement a code of honour to change the attitudes of students regarding academic dishonesty and promote integrity in the academic environment of this institution.

- A judicial system that manages incidents of academic dishonesty should be established.
- Asystem of peer monitoring and peer reporting of academic dishonesty must be developed and implemented.

- Academic integrity policies must be formulated with exact definitions that spell out unacceptable academic behaviour. These policies should reflect a zero tolerance approach, tempered where necessary by a progressive disciplinary process to academic dishonesty, thereby affirming academic integrity as a core institutional value (McCabe \& Pavela 2004:12).

- Special attention should be given to educating students about plagiarism and referencing through introduction of an academic development programme that gives pertinent, rigorous attention to the issues of plagiarism and in particular the referencing of sources, from first year onwards.

- Students should be required to complete a declaration of authenticity when submitting assignments.

- Assignment topics must be changed on a regular basis.

- Combat plagiarism with appropriate disciplinary action when persistent, deliberate transgression occurs.

- Create awareness amongst students that integrity regarding completion of the practical requirements of the programme is a prerequisite for development of the necessary skills to be a safe nurse practitioner.

\section{Recommendations for further studies}

Similar studies could target a variety of nursing education institutions in the country. This would allow generalisation of findings to nursing education in South Africa. Furthermore, the ethical socialisation of nursing students, whereby they internalise the ethical values of honesty, integrity and professional morality of the nursing profession, could be explored.

\section{Conclusion}

The findings revealed that academic dishonesty - particularly related to plagiarism and the completion of assignments is a reality amongst pre-registration nursing students. An alarming finding is that academic dishonesty is not restricted to the classroom, but also affects the practical component of nursing education. Furthermore, the discrepancy between observed and self-reported episodes of cheating behaviour indicates that the incidence of cheating behaviours is probably higher than that revealed by the self-reporting. These findings are a cause for concern in view of the expectation that nursing students should always behave in an ethical manner, and that they should not lack the necessary knowledge and skills to provide high- quality patient care.

\section{Acknowledgements}

The following contributions to the study are acknowledged: I. Smith, Study leader and co-author; M. Kidd, research statistician; and A. Meyer, language editor.

\section{Competing interest}

There were no competing interests and no inappropriate financial or personal gain resulted from this study. 


\section{Authors' contributions}

C.J.T. (Stellenbosch University) was the researcher. I.S. (Stellenbosch University) was the study leader and promoter.

\section{References}

Babbie, E., 2007, The practice of social research, 11th edn., Thomson Wadsworth, Belmont.

Bailey, A.P., 2001, 'Academic misconduct: Responses from deans and nurse educators', Journal of Nursing Education, 40(3), 124-131. PMid:11302540

Basavanthappa, B.T., 2007. Nursing research, 2nd edn., Jaypee, New Delhi. http:// dx.doi.org/10.5005/jp/books/10557

Blankenship, K.L. \& Whitley, B.E., 2000, 'Relation of general deviance to academic dishonesty', Ethics \& Behavior 10(1), 1-12. http://dx.doi.org/10.1207/ S15327019EB1001_1

Brink, H., 2006, Fundamentals of research methodology for health care professionals, 2nd edn., revised by C. van der Walt \& G. van Rensburg, Juta, Cape Town.

Brown, D.L., 2002, 'Spotlight on ... cheating must be okay - everybody does it!', Nurse Educator 27(1), 6-8. http://dx.doi.org/10.1097/00006223-200201000-00010, PMid:11840063

Burns, S.R., Davis, SF, Hoshino, J. \& Miller, R.L., 1998, 'Academic dishonesty: A delineation of cross-cultural patterns', College Student Journal, 32(4):590-597.

Daniel, L.G, Adams, B.N. \& Smith, N.M., 1994, 'Academic misconduct among nursing students: A multivariate investigation', Journal of Professional Nursing, 10(5), 278-288. http://dx.doi.org/10.1016/8755-7223(94)90053-1

Fontana, J.S., 2009, 'Nursing faculty experiences of students' academic dishonesty', Journal of Nursing Education 48(4), 181-185. http://dx.doio rg/10.3928/01484834-20090401-05, PMid:19441633

Gaberson, K.B., 1997, 'Academic dishonesty among nursing students', Nursing Forum, 32(3), 14-21, viewed 7 June 2009, from http://www.find.galegroup.com.ez.sun. ac.za/itx/infomark.do?\&contentSet-IAC-Documents\&type-retrieve\&tabIDT002\&prodID-ONE\&docld-A19996782\&source-gale\&srcprod-AONE\&use GroupName-27uos\&version-1.0

Hall, T.L. \& Kuh, G.D., 1998, 'Honor among students: Academic integrity and honor codes at state-assisted universities', NASPA Journal, 36(1), 12-18.

Harding, T.S., Carpenter, D.D., Finelli, C.J. \& Passow, H.J., 2004, 'Does academic dishonesty relate to unethical behavior in professional practice? An exploratorystudy', Science and Engineering Ethics, 10(2), 311-324. http://dx.doi.org/10.1007/s11948-004-0027-3, PMid:15152857

Hilbert, G.A., 1985, 'Involvement of nursing students in unethical classroom and clinical behaviours', Journal of Professional Nursing, 1(4), 230-234. http://dx.doi. org/10.1016/S8755-7223(85)80160-5

Hilbert, G.A., 1987, 'Academic fraud: Prevalence, practices, and reasons', Journal of Professional Nursing, 3(1):39-45. http://dx.doi.org/10.1016/S87557223(87)80026-1

Jordan, A.E., 2001, 'College student cheating: The role of motivation, perceived norms, attitudes, and knowledge of institutional policy', Ethics \& Behavior, 11(3), 233-247. http://dx.doi.org/10.1207/S15327019EB1103_3

Kenny, D., 2007, Student plagiarism and professional practice, Nurse Education Today, 27(1):14-18. http://dx.doi.org/10.1016/j.nedt.2006.02.004, PMid:16624455

Lambert, E.G., Hogan, N.L. \& Barton, S.M., 2003, 'Collegiate academic dishonesty revisited: What have they done, how often have they done it, who does it, and why did they do it? Electronic Journal of Sociology, 7(4), viewed 8 June 20009 from http://www.sociology.org/content/vol7.4/lambert_etal_html
Lewenson, S.B., Truglio-Londrigan, M. \& Singleton, J., 2005, 'Practice what you teach: A case study of ethical conduct in the academic setting', Journal of Professional Nursing, 21(2), 89-96. http://dx.doi.org/10.1016/j.profnurs.2005.01.006, Nursing, 21(2)

Lim, V.K. \& See, S.K., 2001, 'Attitudes toward, and intentions to report, academic cheating among students in Singapore', Ethics \& Behavior, 11(3):261-274. http:// dx.doi.org/10.1207/S15327019EB1103_5

Logue, R., 2004, 'Plagiarism: The internet makes it easy', Nursing Standard, 18(51):4043

McCabe, D.L., 2009. Academic dishonesty in nursing schools: An empirical investigation. Journal of Nursing Education 48(11), 614-623. http://dx.doi. investigation. Journal of Nursing Education 48(11),
org/10.3928/01484834-20090716-07, PMid:19650608

McCabe, D.L., Butterfield, K.D. \& Treviño, L.K., 2006, 'Academic dishonesty in graduate business programs: Prevalence, causes, and proposed action', Academy of Management Learning \& Education, 5(3), 294-305. http://dx.doi.org/10.5465/ AMLE.2006.22697018

McCabe, D.L. \& Pavela, G., 2004, 'Ten (updated) principles of academic integrity: How faculty can foster student honesty', Change, 36(3), 10-15. http://dx.doi. org/10.1080/00091380409605574

McCabe, D.L. \& Treviño, L.K., 1997, 'Individual and contextual influences on academic dishonesty', Research in Higher Education, 38(3), 379-396. http://dx.doi. org/10.1023/A:1024954224675

Mccabe, D.L., Treviño, L.K. \& Butterfield, K.D., 2001, 'Cheating in academic institutions: A decade of research', Ethics \& Behavior, 11(3), 219-232. http:// dx.doi.org/10.1207/S15327019EB1103_2

Mouton, J. 2001, How to succeed in your master's and doctoral studies: A South African guide and resource book, Van Schaik, Pretoria.

Newstead, S.E., Franklin-Stokes, A. \& Armstead, P., 1996, 'Individual differences in student cheating', Journal of Educational Psychology, 88(2), 229-241. http:// dx.doi.org/10.1037/0022-0663.88.2.229

Nonis, S. \& Swift, C.O., 2001, 'An examination of the relationship between academic dishonesty and workplace dishonesty: A multi-campus investigation', Journal of Education for Business, 77(2), 69-77. http://dx.doi org/10.1080/08832320109599052

Olasehinde-Williams, F.A.O., Abdullah, I.O.E. \& Owolabi, H.O., 2003, 'The relationship between background variables and cheating tendencies among students of a federal university in Nigeria', Nigerian Journal Educational Foundations, 6(1), 68-79.

Park, C., 2003, 'In other (people's) words: Plagiarism by university students - literature and lessons', Assessment \& Evaluation in Higher Education, 28(5), 471-488. $\mathrm{http}: / / \mathrm{dx}$.doi.org/10.1080/02602930301677

Paterson, B., Taylor, L. \& Usick, B., 2003, 'The construction of plagiarism in a schoo of nursing', Learning in Health and Social Care, 2(3), 147-158. http://dx.doi. org/10.1046/j.1473-6861.2003.00047.x

Poggenpoel, M. 1998, 'Data analysis in qualitative research', in AS de Vos (ed.), Research at grass roots, pp. 334-353, Van Schaik, Pretoria.

Schmidt, S.D., 2006, 'Cheating: An ethical concern for nursing educators', Kansas Nurse, 81(1), 1-2.

Searle, C., 2000, Professional practice: A Southern African nursing perspective, 4th edn., Heinemann, Sandton.

South African Government, 1978, Nursing Act, No. 78 of 1978, Government Printer, Pretoria.

Tanner, C.A., 2004, 'Moral decline or pragmatic decision making? Cheating and plagiarism in perspective', Journal of Nursing Education, 43(7), 291-292.

Turner, S.P. \& Beemsterboer, P.L., 2003, 'Enhancing academic integrity: Formulating effective honor codes', Journal of Dental Education, 67(10), 1122-1129. PMid:14587677

Whitley, B.E., 1998, 'Factors associated with cheating among college students: A review', Research in Higher Education, 39(3), 235-274. http://dx.doi. org/10.1023/A:1018724900565 